\title{
"SHARING IS CARING": DESIGNING A VALUE-SENSITIVE MHEALTH PLATFORM FOR SHARING TYPE 1 DIABETES MANAGEMENT WITHIN FAMILIES
}

\author{
Elettra Oleari ${ }^{1}$, Clara Pozzi ${ }^{2}$, Francesco Sardu ${ }^{2}$, Francesca Sacchitelli², Virginia Sanchini ${ }^{2}$ \\ and Alberto Sanna ${ }^{1}$ \\ ${ }^{I}$ Ospedale San Raffaele, Milan, Italy \\ ${ }^{2}$ Fondazione Centro San Raffaele, Milan, Italy
}

\begin{abstract}
Within a mobile-technology enhanced educational framework, this study investigates needs and expectations of children (aged 8-14) with type 1 diabetes, and their parents, to define the functionalities of PAL Inform, a web-based monitoring module. The aim is to design it as a tool for parents to be informed on the educational progresses, as well on diabetes-related data, of their children without violating their values (privacy, trust, autonomy). Through a set of co-design activities, carried out with 39 children and 45 parents, it was possible to define which kind of information parents would monitor and children (especially pre-adolescents), in turn, would share, without compromising family dynamics: i.e. glycaemic values and trends, insulin doses, carbohydrates intake, generic emotional status, educational progresses on diabetes-related knowledge. Leveraging on these insights, a set of functional requirements was elicited for the future monitoring module implementation.
\end{abstract}

\section{KEYWORDS}

Type 1 Diabetes, Children, Self-Management, mHealth, Focus Group, Role Playing

\section{INTRODUCTION}

Type 1 Diabetes Mellitus (T1DM) is the most pervasive endocrine-metabolic condition in childhood, with more than 28.000 newly diagnosed worldwide, from 0 to 19 years old, in 2017 (International Diabetes Federation 2017). Diabetes self-management plays a crucial role for young patients in order to maintain health-related quality of life and to avoid long-term complications, like heart and blood vessel diseases or nerves, kidneys and eyes damages. However, it is not an easy goal to attain for the younger ones, since it requires long-term motivation and perseverance (Hoey et al. 2001). Moreover, the onset of T1DM raises new challenges for the entire family as, on the one hand, many new notions have to be learnt, and, on the other, the whole family has to find a way for restoring an internal balance, adapting to the diagnosis and new daily routines (Marshall et al. 2009; Jaser 2009). The final aim of this process is the gradual acquisition of autonomy by the side of children and/or adolescents in the management of their condition, including blood glucose monitoring, insulin administration and carbohydrates (CHO) counting (Schilling et al. 2002).

Autonomous management of diabetes in children/adolescents is strongly affected by a wide range of personal and environmental factors, such as their developmental stage and the level of support and care provided by the reference adults, especially their parents (Naranjo 2014; Scott 2013; Wu et al. 2014). In fact, several studies show that a shared responsibility of T1DM within the family is consistently associated with better adherence and health functioning across adolescence (Helgeson 2008; Wysocki 2009). Moreover, parental involvement in diabetes management reveals to be essential to the maintenance of psychological health, glycaemic control, and the development of self-care behaviours in young patients (Anderson 1997; Anderson and Wolpert 2004; Berg et al. 2008). In this view, children are expected to be more responsible towards diabetes care when they reach pre-adolescence; however, at this age, adherence and glycometabolic control decrease. Transition into adolescence, in fact, is characterized by oscillations between dependence on 
parents and desire of independence, with feelings of increased self-reliance and autonomy (Steinberg and Silverberg 1986). A chronic condition like diabetes creates a situation of dependence precisely in the phase in which adolescents feel the greater pressure to define themselves as separate individuals (Coupey and Cohen 1984). To avoid such complications, current treatment standards foster the importance of continuous parental involvement in T1DM managing process, ranging from support during childhood to supervision during adolescence, through intervention programs, that aim to reinforce parental disease acceptance, paternal involvement, family warmth, cohesion and supportive attitudes (Berg et al. 2008; Young et al. 2014).

In this context, technology revealed to play an important role in supporting self-management of chronic conditions such as T1DM (Franklin et al. 2008; Holtz and Lauckner 2012). Amongst them, mobile health (mHealth) applications have been shown as promising tools, thanks to their easy access and wide usage, particularly by young people, potentially capable of improving patients' and families education (Cafazzo et al. 2012; Calvo et al. 2014; Frøisland et al. 2012) and enhancing communication with care providers in effective ways (Holtz et al. 2017). On the wake of these evidences, the PAL project (grant agreement $\mathrm{n}^{\circ}$ 643783) aims to develop a Personal Assistant for healthy Lifestyle (PAL), a System that helps children/pre-adolescents, parents and Health Care Professionals (HCPs) to advance T1DM self-management, so as to establish an adequate shared patient-family-caregiver responsibility before adolescence.

The present work aims to empirically investigate needs and expectations of families dealing with T1DM, in order to detect characteristics, contents and functionalities of a value-sensitive interface, called $P A L$ Inform. This represents a monitoring and informing tool for parents to improve their knowledge on children's self-management, while fostering a positive attitude towards T1DM shared experiences and communication, without violating children's private sphere. Drawing from these premises, a set of co-design methodologies, i.e. Focus Group and Role Playing sessions, have been put in place. Data collected have been then analyzed and formalized into functional specifications to implement PAL Inform in such a way as to satisfy all the end-users desiderata and make it actually usable in daily lives. The study has been designed and conducted by a pool of experts in the fields of psychology, mHealth technologies, service design and bioethics in order to have comprehensive scientific basis on which to structure the research. The paper is organised as follows: Section 2 is devoted to the presentation of the PAL Educational Framework; Section 3 presents the experimental procedure and Section 4 study results. Finally, the discussion reflects on some of the insights gained during the study and presents an anticipation of the future developments of this work.

\section{PAL SYSTEM EDUCATIONAL FRAMEWORK}

The PAL System is structured as a multicomponent platform connected to a central knowledge-based Artificial Intelligence (AI) (Figure 1). PAL technologies for children/pre-adolescents are a suite of mHealth games linked to a conversational agent, both embodied (the PAL robot) and virtual (its avatar). Therefore, children can play with the PAL robot in contexts like hospitals, and with its avatar at home using the MyPAL application for tablets, which comprises a quiz, various mini-games, and an interactive diary where to input data regarding T1DM (e.g. glucose values, insulin doses, carbohydrates' intake) and other activities (e.g. sports and emotions). Thanks to these interactions, children are supposed to acquire knowledge and to be motivated in pursuing correct behaviors, so as to better manage their conditions (Peters et al 2019).

The educational contents for children/pre-adolescents are created and monitored by HCPs, who set personalized T1DM self-management learning goals through the PAL Control interface (Peters et al 2017). These goals, strictly linked with daily-life situations and tuned on specific age ranges, are supposed to be pursued in time by children through the activities and games proposed by MyPAL app and the PAL agent. For example, to autonomously participate to a birthday party it is important to be able to count $\mathrm{CHO}$; therefore PAL will propose to the child quiz questions and levels of the sorting game on this topic (Figure 1).

The third component, which represents the subject of this contribution, is named PAL Inform. It is meant to be a browser interface allowing parents to have a dedicated access, in order to see the PAL-mediated educational progresses of their children and data regarding their T1DM management retrieved by the System (e.g. glycaemia values inserted in the diary of $M y P A L$ app). 

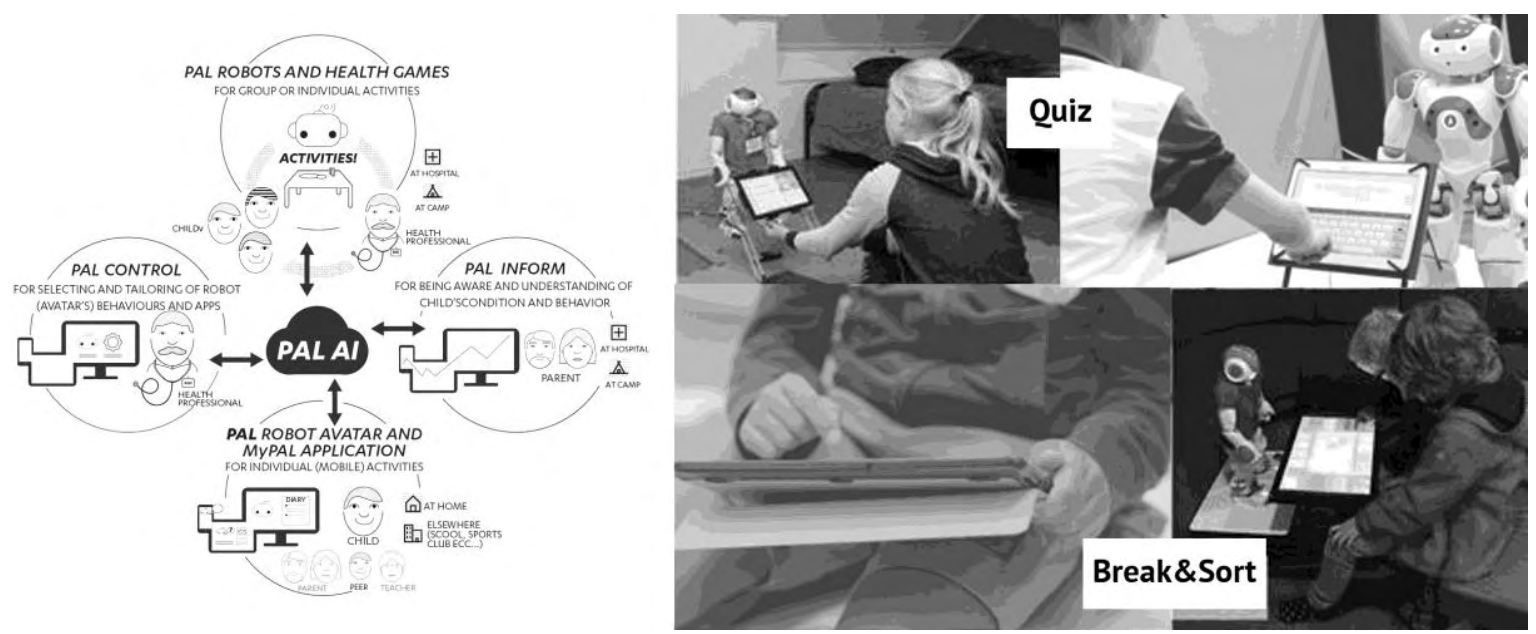

Figure 1. On the left: the PAL technological components, with the details of their specific end-users and application settings; on the right: children playing educational activities with the PAL robot and its avatar

\section{DESIGNING PAL INFORM: AN USER-CENTERED INVESTIGATION}

A dedicated user-centered investigation has been devised in order to derive coherent, and respectful of the various points of view (value-sensitive), functional specifications for PAL Inform. The study presents the following endpoints: (i) to understand which are, according to parents, the determining factors (e.g.: knowledge, understanding, trust) able to offer their children a support, through a shared responsible process, in achieving an autonomous management of their disease; (ii) to explore parents' needs and expectations towards a technological tool, able to provide them with a certain level of monitoring regarding different aspects of their children's T1DM management; (iii) to understand children's opinions on $P A L$ Inform and what kind of information they would be willing to share without considering it as an intrusion.

\subsection{Materials and Method}

A set of formal co-design methods has been outlined to create a proper and engaging research environment:

1. Structured Questionnaires are quantitative research methods, made up by direct and close questions. For the present contribution, a specific Questionnaire ${ }^{1}$ was drawn for the participating parents to explore: $(i)$ their experiences with day-life management of T1DM, with particular attention to the shared responsibilities on diabetes tasks - see Q1, Q2, (ii) the perceived level of autonomy of their children and parents' feelings about it - see Q3, Q4, Q10, (iii) the principal parental worries linked to diabetes - see Q6 to Q9 and (iv) their desires and expectations regarding Pal Inform - see Q11 to 16. The questionnaire takes inspiration from already existing clinical instruments (Lewin et al. 2009; Streisand et al. 2005) and the researchers' clinical experience with T1DM young patients and, since it was not already a published or validated tool, it has been internally validated in its contents and structure by a pool of experts ( 2 psychologists and 1 pediatric diabetologist) of San Raffaele Hospital, before its use.

2. Role Play is an experiential activity originating from the Classical Psychodrama (Castro et al. 1993; Moreno 1973; Robinson 2004), which provides participants with an active experience simulating a real-life situation, characterized by certain social roles. In this case, the aim was to make children/pre-adolescents assuming both their own role and their parents' one regarding T1DM management and education, in order to find possible solutions about PAL Inform and subsequently compare the gained insights with those derived by the (real) adults participating;

\footnotetext{
${ }^{1}$ For the full questionnaire see: http://www.pal4u.eu/wp-content/uploads/Structured-Questionnaire-for-Parents.pdf
} 
3. Focus Group (Morgan 1998; Migliorini and Rania 2001) is a qualitative research technique, where a group of people is invited to discuss on a theme. Here, this was used to derive parents' needs, issues and desiderata regarding a technology-enhanced monitoring of their children T1DM management.

This research protocol has been approved by the Ethics Committee of San Raffaele Hospital (Milan, Italy), protocol number PAL-643783-5, in the session of the 13/07/2017.

\subsection{Measures}

Based on the exploratory nature of the study, an inductive qualitative content analysis was performed to derive the key areas of interest for the PAL end-users (Krippendorff 2004). Frequency of occurrence of questionnaire's and templates' responses, participants' verbal responses and discussions from the audio/video recordings of the activities, as well as researcher's notes during their execution, were taken into account to identify the key themes emerged in the investigation.

\subsection{Participants}

The activities took place during two educational Camps for children/ pre-adolescents with T1DM: the former held in August 2017 for pre-adolescents aged 11 to 14 y.o. (without their parents), the latter in October 2017 for children aged 8 to 10 y.o. with their families. To take part to the activities, participants had to sign a specific informed consent (in case of the minors both the parents or legal tutors had to sign it), and had to be native language speakers. Only the parents compiling the on-line format of the Structured Questionnaire were excused from signing the informed consent as data collection in this case was anonymous (see Section 3.4).

In total, 39 of 44 pre-adolescents (mean age $=12.73$ y.o, std.dev $=0.79$ ) attending the August camp and 33 amongst their parents, as well as 6 families participating at the October camp (i.e. all the 12 parents) participated to the study. Notably, researchers chose to explore only expectations and perceptions of the pre-adolescents group regarding PAL Inform, leaving aside those of the younger ones. The rationale behind this choice is that, as already explained, preadolescence is a critical developmental phase generally characterized by changes in relationships with adults, which influences, and is influenced, by the management of a chronic disease (Foster et al. 2016). Children, instead, are more parents' dependent on T1DM management.

\subsection{Procedure}

At the diabetes camps, dedicated rooms were set up with all the needed materials to carry out the activities, which were supervised by a moderator and by a psychologist, and their audio/video recordings.

Structured Questionnaire for parents - parents of both the age groups were involved: those of the younger children filled in the questionnaire before starting the Focus Group session, while those of the older ones were provided an online version of the same questionnaire and had the chance to complete it anonymously at home while their children were at the August camp.

Role Play sessions, for pre-adolescents of 11 to 14 y.o. at the August camp - participants were randomly assigned to one of two groups (from 3 up to 5 components each) on the basis of the role they were supposed to interpret: the "parents" group and the "children" group. Participants were asked to think about a possible future platform (PAL Inform) that would help families with children of their age to manage T1DM and learn about it. The two groups imagined which functions they would like to find on this tool and for which purposes, thinking to real situations of everyday-lives, helped by a set of "situation card", like for example a school trip or sports. After discussing on these, each group wrote all their considerations down on dedicated templates, which are meant to help them focusing on the following aspects: the kind of information they would like (or not) to share, the reasons of those choices and the corresponding priority orders.

Focus Group activity for parents of children of 8 to 10 y.o. at the October camp - the 12 parents were invited to discuss their needs and wishes about PAL Inform. The parents had at disposal, to elicit the discussion, the same templates used by children during the Role Playing. 


\section{RESULTS}

We first analyzed the Structured Questionnaire for parents to characterize the parental participant's population and gain a first preliminary overview of: $(i)$ the main needs and worries of parents regarding their children's T1DM management and (ii) expectations about PAL Inform. Then, all the dialogs in the audio/video recordings of the Role Play and Focus Group were transcribed, in order to obtain a database of contents compatible with the other materials collected in the activities (i.e. templates formats and researchers' notes) and suitable to be studied by an open coding process (Flick 2009). All the raw data were then reviewed and annotated by the research team to identify recurrent themes, from which grouping data into broader categories expressing the same concepts, focusing the attention on how to properly share data on T1DM management and on T1DM education within the family. These themes were therefore compared with the preliminary insights of the Structured Questionnaire so as to obtain a final list of key topics to be translated into functional requirements for the PAL Inform future implementation (see Section 5).

\subsection{Characterization of the Parental Pool}

Data collected from the Questionnaire revealed a parental attitude towards the care of their children in line with the level of autonomy expected by the two age groups (Q1 to Q3). The younger children share the responsibility of the major T1DM tasks, i.e. glycemic checks and insulin injections, with their parents: 10 out of 12 parents $(83 \%)$ stated that these tasks are performed alternately by themselves and their children. Pre-adolescents, instead, are more independent and usually manage on their own the glycaemia (24/33 cases, $73 \%$ of the pool) and the injections (23/33 cases, 70\%). The major parental concerns, in both the groups, are linked to possible children's diabetes-related malaises far from their direct control, like severe hypoglycemic episodes away from home - e.g. Q5: 9/12 and 14/33 cases, Q8: 6/12 and 26/33 cases, Q9: 11/12 and 17/33 cases for children and pre-adolescents respectively. However, the idea that their children will improve in autonomy towards T1DM as time passes (Q4), makes all the parents confident and is reported as a stimulus for reassuring their children on their own self-management capabilities. Parents would like, through $P A L$ Inform, to globally monitor T1DM self-management of their children, especially (Q14): blood sugar levels $-12 / 12$ and 23/33 cases, CHO intake $-6 / 12$ and 8/33 cases and insulin dosages $-4 / 12$ and 11/33 cases for children and pre-adolescents respectively. Moreover, on this basis, parents would like to interact if necessary with their children on T1DM related topics, e.g. decide together the insulin dosage - Q15: 7/12 and $19 / 33$ cases. The need for monitoring T1DM-related information is thought to be mainly directed at the time spent at school, Q13: 9/12 and 14/33 cases, or sport/free activities, Q13: 8/12 cases.

\subsection{Role Play Sessions for Pre-Adolescents of 11 to 14 y.o}

Overall, 5 Role Play sessions (i.e. 10 groups of children, 5 impersonating the parents and 5 themselves) took place during the August camp. The collected insights are grouped in two clusters, which are presented in the following with a fine grained description of the main sub-topics emerged:

Sharing data regarding TIDM management - to elicit the discussion among the participants, the templates covered the entire range of information which are usually pertinent to T1DM self-management and could be retrieved through the use of the MyPAL diary in real-life situations: (i) data on glycemic control (e.g. timing and values of the glycaemic checks), (ii) data on meals and CHO counting, (iii) data on the timing and entity of insulin dosages, (iv) data on physical activity and other events, $(v)$ data on emotional status. Both the "parents" and "children" groups, agreed on the importance of sharing information regarding glycemic values (10/10 groups), CHO counting (5/5 "parents", 4/5 "children") and insulin doses (5/5 "parents", 4/5 "children"). An aspect that was not enthusiastically accepted by the "children" group (2/5 groups), and in any case did not find a great interest either by the "parents" group (2/5 groups), is the possibility to share the number and details of meals away from home. Differently, with respect to additional information on sports, all the "children" groups were willing to share it in its entirety, while the "parents" groups showed interest only for type and duration of the exercises. Lastly, most of the "parents" were not willing to be informed on emotion-related data (1/5 groups) and "children" were prone to share only an overview of their feelings, like a "mood of the day" emoticon (4/5 groups), but not personal information written within the dedicated $M y P A L$ diary section. 
Sharing the educational progresses on T1DM - the activity also focused on the possibility of sharing the T1DM educational path envisioned by the PAL System and the T1DM personalized goal achievements set by HCPs. There was a clear positive attitude in the "children" group towards the sharing of these kinds of data (4/5 groups); the "parents" groups, instead, were split between those who were afraid of being intrusive (3/5 groups) and those who stressed the importance of understanding any improvements towards autonomy (2/5).

\subsection{Focus Group Activity for Parents of Children Aged 8 to 10 y.o}

As for the Role Playing activity, the discussion held between the 12 parents focused on the following topics:

Sharing data regarding TIDM management - through PAL Inform, parents would like to monitor glycemic values (12 out of 12) and corresponding timing (10/12 cases), as long as the insulin doses (10/12 cases) and the amount of CHO intake per meal (12/12 cases). In addition to those, parents would like to monitor, in relation to the corresponding glycemic trends, the duration of eventual sport activities (8/12 cases). Interestingly, knowing the emotional status of their children, derived from the MyPAL diary, is perceived as an added value to the daily therapy management (10/12 cases). From an extract of the parents' discussion: “... to understand how they [emotions] could influence [my child's] glycaemia and help him in managing the therapy".

Sharing the educational progresses on T1DM - all the parents showed an interest in being aware of the progresses in the T1DM educational path of their children, as well as in the fulfilment of their goals, in order to help them; if needed (2/12 cases), they praise and reward them whenever they accomplish a new goal (6/12 cases) and understand their actual improvements towards autonomy (4/12 cases).

An overview of the all the findings of the PAL Inform co-design investigation is reported in Table 1.

Table 1. Overview of the results obtained from the PAL Inform investigation, with the details of the T1DM-related topics under analysis, where Yes or No indicates the willingness (or not) to share/know the specific type of data

\begin{tabular}{|c|c|c|c|c|c|c|}
\hline & & \multirow{2}{*}{\multicolumn{2}{|c|}{ QUESTIONNAIRE }} & \multirow{2}{*}{\multicolumn{2}{|c|}{ ROLE PLAY }} & \multirow{3}{*}{$\begin{array}{c}\text { FOCUS GROUP } \\
\text { Parents } \\
(8-10 \text { y.o })\end{array}$} \\
\hline & & & & & & \\
\hline & & $\begin{array}{c}\text { Parents } \\
(8-10 \text { y.o })\end{array}$ & $\begin{array}{c}\text { Parents } \\
\text { (11-14 y.o) }\end{array}$ & "Children" & "Parents" & \\
\hline \multirow[t]{2}{*}{ Glycaemia } & Glycaemic Values & Yes & Yes & Yes & Yes & Yes \\
\hline & Number of insertion & No & No & No & No & No \\
\hline Insulin & Insulin doses & Yes & Yes & Yes & Yes & Yes \\
\hline \multirow[t]{2}{*}{ Nutrition } & CHO counting & Yes & No & Yes & Yes & Yes \\
\hline & Meal details & 1 & I & No & No & No \\
\hline Activities & Sport & Yes & Yes & Yes & Yes & Yes \\
\hline \multirow{2}{*}{ Emotional Status } & $\begin{array}{l}\text { Overview } \\
\text { (emoticons) }\end{array}$ & No & No & Yes & Yes & Yes \\
\hline & Details (notes) & No & No & No & No & No \\
\hline \multirow[t]{2}{*}{ T1DM education } & Goal achievement & I & I & Yes & Yes/No & Yes \\
\hline & Overall progress & I & I & Yes & Yes/No & Yes \\
\hline
\end{tabular}

\section{DISCUSSION AND FUTURE PERSPECTIVES}

The present study aims to explore and collect parents' and their children's needs, values and expectations regarding Pal Inform, a browser module for monitoring data on T1DM management and education within the family. A suite of co-design activities was exerted to understand which kind of information may have been smoothly shared and, on the contrary, which ones may have represented a source of tension between children (especially the pre-adolescent ones) and their parents, thus making PAL Inform counter-productive.

Despite an overall positive parental perception of children's autonomy in both the age groups, a generalized need of control emerged. Indeed, all the parents expressed their wish to monitor their children, especially during those hours in which they are not with them, such as at school and during free/sport time. Inasmuch as they are concerned of possible diabetes-related critical episodes, such as hypoglycemic crises, blood sugar levels represent the parameter the parents care mostly. In this regard, it is interesting to note that both children and parents figure PAL Inform as an useful tool for sharing data related to T1DM therapy management, i.e. glycaemia values and insulin doses, as supposedly able to provide a mutual reassurance. The nutritional domain, instead, represents an area in which children are reluctant to share too much details 
with their parents. While carbohydrates counting is considered as a parameter worthwhile to be shared, pre-adolescents appear unwilling to disclose the details of their daily food intake. This result is, however, in line with the literature, as food transgressions are quite common during this age (Kelly et al. 2005). Regarding data on the emotional status, children want to share only superficial data, with a refusal towards more details. This is observed in parents as well, thus showing respect for the privacy of their children together with an attitude of non-intrusiveness. Parents and children, moreover, demonstrate a common interest in sharing information regarding diabetes-knowledge acquisition and progresses, and the related motivations are all connected to the empowerment of trust between family members: "... so our parents could trust us more" [citation from one of the children groups during the Role Play session], "... so I can realize his level of awareness and help him in case of need" [citation from one of the parents during the Focus Group"].

To conclude, on the wake of these results, Table 2 reports the functional requirements elicited for the upcoming implementation of PAL Inform. Once the module will be up and running, an user experience evaluation is going to be put in place in order to verify its effectiveness and reliability in real-life usage.

Table 2. List of PAL Inform Functional Requirements

\begin{tabular}{|c|c|c|}
\hline $\begin{array}{c}\text { Requirement } \\
\text { number }\end{array}$ & Description & Example \\
\hline 1 & $\begin{array}{l}\text { PAL Inform has to allow parents to visualize children's glycaemic } \\
\text { data }\end{array}$ & $\begin{array}{l}\text { - Time of the glycaemic test } \\
\text { - Glycaemia value }\end{array}$ \\
\hline 2 & $\begin{array}{l}\text { PAL Inform has to show when glycaemia goes above/ below } \\
\text { certain thresholds }\end{array}$ & $\begin{array}{l}\text { Setting personalized hypo/ hyper- } \\
\text { glycaemia values }\end{array}$ \\
\hline 3 & PAL Inform has to display children's glycaemic trend in time & $\begin{array}{l}\text { Customizable data visualization: } \\
\text { daily, weekly, monthly }\end{array}$ \\
\hline 4 & PAL Inform has to display each dose of insulin performed & $\begin{array}{l}\text { - Time of the injection } \\
\text { - Amount of insulin }\end{array}$ \\
\hline 5 & $\begin{array}{l}\text { PAL Inform has to display the number of } \mathrm{CHO} \text { assumed for each } \\
\text { meal }\end{array}$ & $\begin{array}{l}\text { - Time } \\
\text { - Quantity }\end{array}$ \\
\hline 6 & PAL Inform has to display the total of $\mathrm{CHO}$ assumed in a day & - Time \\
\hline 7 & PAL Inform has to display the sport activity/ies performed & $\begin{array}{l}\text { - Type of activity } \\
\text { - Last glycemic value before sport }\end{array}$ \\
\hline 8 & $\begin{array}{l}\text { PAL Inform has to display a summary of the emotional status but } \\
\text { NOT its details }\end{array}$ & - Type of emoticon \\
\hline 9 & PAL Inform has to notify when the child achieves a T1DM goal & $\begin{array}{l}\text { - Name and Level of the goal } \\
\text { - When it has been achieved } \\
\text { - Brief description of the goal }\end{array}$ \\
\hline 10 & $\begin{array}{l}\text { PAL Inform has to display meaningful aggregated data on a } \\
\text { customizable timeline }\end{array}$ & $\begin{array}{l}\text { - Glycemic Value } \\
\text { - Insulin Bolus } \\
\text { - CHO intakes }\end{array}$ \\
\hline 11 & PAL Inform has to enable parents to send their children messages & - Discuss on the dosage of insulin \\
\hline
\end{tabular}

\section{ACKNOWLEDGEMENT}

This work is funded by the EU Horizon PAL project (grant nr. 643783). We wish to thank all the participating families and the "Sostegno70- insieme ai ragazzi diabetici" patients' association for their support.

\section{REFERENCES}

Anderson BJ, Ho J, Brackett J et al. ,1997. Parental involvement in diabetes management tasks: relationships to blood glucose monitoring adherence and metabolic control in young adolescents with insulin-dependent diabetes mellitus. Journal of Pediatrics, 130(2): 257-65.

Anderson BJ and Wolpert HA, 2004. A developmental perspective on the challenges of diabetes education and care during the young adult period. Patient Education and Counseling 53(3): 347-352.

Berg CA, Butler JM, Osborn P, et al., 2008. Role of parental monitoring in understanding the benefits of parental acceptance on adolescent adherence and metabolic control of type 1 diabetes. Diabetes Care 31(4):678-83. 
Cafazzo J, Casselman M, Hamming N, et al., 2012. Design of an mHealth App for the Self-management of Adolescent Type 1 Diabetes: A Pilot Study. Journal of Medical Internet Research 14(3): e70.

Calvo RA, Pardo a, Zhao Y, et al., 2014. TransitionMate: A Mobile Application for Chronic Illness Transition Support. Workshop on Supporting Autonomy in Technology Design, pp.1-4.

Castro B, Castro D, and Poznanski R, 1993. Use of role-playing in child psychotherapy and psychopedagogy. Annales Médico-Psychologiques 151(7): 535-7.

Coupey SM and Cohen MI, 1984. Special considerations for the health care of adolescents with chronic illness. Pediatric Clinics of North America 31:211-219.

Flick, U, 2009. An Introduction to Qualitative Research. SAGE. ISBN 9781446241318.

Foster C, Bellando J and Wang Y-CA, 2016. Diabetes Control and Adherence in Adolescence. Pediatric Annals 45(9): e327-e331.

Franklin VL, Greene A, Waller A et al., 2008. Patients' engagement with "Sweet Talk" - a text messaging support system for young people with diabetes. Journal of Medical Internet Research 10(2):e20.

Frøisland DH, Eirik $\AA$ and Finn S, 2012. Improving Diabetes Care for Young People With Type 1 Diabetes Through Visual Learning on Mobile Phones: Mixed-Methods Study. Journal of Medical Internet Research 14(4):e111.

Helgeson VS, Reynolds KA, Siminerio Let al., 2008. Parent and adolescent distribution of responsibility for diabetes selfcare: links to health outcomes. Journal of Paediatric Psychology 33(5):497-508.

Hoey H, Aanstoot H-J, Chiarelli F, et al., 2001. Good Metabolic Control Is Associated With Better Quality of Life in 2,101 Adolescents With Type 1 Diabetes. Diabetes Care 24(11): 1923-8.

Holtz B and Lauckner C, 2012. Diabetes management via mobile phones: a systematic review. Telemedicine journal and e-health 18(3):175-184.

Holtz BE, Murray KM, Hershey DD et al., 2017. The design and development of MyT1DHero: A mobile app for adolescents with type 1 diabetes and their parents. Journal of Telemedicine and Telecare 0(0): 1-9.

International Diabetes Federation, 2017. Diabetes Atlas Eighth edition 2017.

Jaser S, 2009. Family Interaction in Pediatric Diabetes. Current Diabetes Reports 11(6): 480-485.

Kelly SD, Howe CJ, Hndler JP, et al., 2005. Disordered eating behaviors in youth with type 1 diabetes. Diabetes Educator 31(4): 572-583.

Krippendorff K, 2004. Content Analysis: An Introduction to Its Methodology. Sage Publications.

Lewin AB, LaGreca AM, Geffken GR, et al, 2009. Validity and reliability of an adolescent and parent rating scale of type 1 diabetes adherence behaviors: the Self-Care Inventory (SCI). J Pediatr Psychol. 34(9):999-1007.

Marshall M, Carter B, Rose K, et al, 2009. Living with type 1 diabetes: Perceptions of children and their parents. Journal of Clinical Nursing 18(12): pp.1703-1710.

Migliorini L and Rania N, 2001. I focus group: uno strumento per la ricerca qualitativa. Animazione Sociale, pp.82-88.

Moreno J, 1973. Psicodramma e vita. Rizzoli Editore.

Morgan D, 1998. The Focus Group Guidebook. Available at: http://sk.sagepub.com/books/the-focus-group-guidebook.

Naranjo D, Mulvaney S, McGrath M et al., 2014. Predictors of self-management in pediatric type 1 diabetes: individual, family, systemic, and technologic influences. Current Diabetes Reports 14:544.

Peters, R. et al, 2017. Guidelines for Treebased Learning Goal Structuring. Proceedings of the 22Nd International Conference on Intelligent User Interfaces (IUI '17). ACM, New York, NY, USA, pp. 401-405.

Peters, R. et al, 2019. Usability of the PAL Objectives Dashboard for Children's Diabetes Self-Management Education. Proceedings of the 5th International Conference on e-Society, e-Learning and e-Technologies, Vienna, Austria.

Robinson DT, 2004. The SAGE Encyclopedia of Social Science Research Methods.

Schilling LS, Grey M and Knafl KA, 2002. The concept of self-management of type 1 diabetes in children and adolescents: an evolutionary concept analysis. Journal of Advanced Nursing 37(1):87-99.

Scott LK, 2013. Developmental Mastery of Diabetes-Related Tasks in Children. Nursing Clinics of North America 48(2): 329-342.

Steinberg L and Silverberg SB, 1986. The vicissitudes of autonomy in early adolescence. Child Development 57, 841-851.

Streisand R, Swift E, Wickmark T, et al, 2005. Pediatric Parenting Stress Among Parents of Children with Type 1 Diabetes: The Role of Self-Efficacy, Responsibility, and Fear, Journal of Pediatric Psychology, 30(6): 513-521

Wu YP, Rausch J, Rohan M, et al, 2014. Autonomy support and responsibility-sharing predict blood glucose monitoring frequency among youth with diabetes. Health psychology: official journal of the Division of Health Psychology, American Psychological Association, 33(10): 1224-1231.

Wysocki T, Nansel TR, HolmbeckGN, et al., 2009. Collaborative involvement of primary and secondary caregivers: associations with youths' diabetes outcomes. Journal of Pediatric Psychology. 34(8):869-81.

Young MT, Lord JH, Patel NJ et al., 2014. Good cop, bad cop: quality of parental involvement in Type 1 Diabetes management in youth. Current Diabetes Reports 14(11): 546. 